\title{
Prevalence and Antibiotic Susceptibility Pattern of Escherichia Coli Isolated from Urine Samples of Urinary Tract Infection Patients
}

\author{
Farouk S. Nas ${ }^{1}$, Muhammad Ali ${ }^{2 *}$, Muhammad S. Abdallah ${ }^{3}$, Abubakar U. Zage \\ ${ }^{1}$ Department of Biological Science, Bayero University Kano, Nigeria \\ ${ }^{2}$ Department of Microbiology, Federal University Gusau, Nigeria \\ ${ }^{3}$ Desert Research Monitoring and Control Centre, Yobe State University Damaturu, Nigeria \\ ${ }^{4}$ Department of Microbiology, Kano University of Science and Technology Wudil, Nigeria
}

*Corresponding Author: Muhammad Ali, Department of Microbiology, Federal University Gusau, Nigeria.E-mail: alimuhd4real@gmail.com

\begin{abstract}
The study was aimed to determine the prevalence and antibiotic Susceptibility pattern of Escherichia coli isolated from urinary tract infection patients in Kano, Nigeria. A total of 50 (21 males and 29 females) urine samples were collected from UTI patients attending urology clinic of Aminu Kano Teaching Hospital Kano for period of 6 month from December 2016 to May, 2017. Ten (10) ml of each urine sample was centrifuged at 2000 revolution per minute (rpm) for 5 minutes, the supernatant was discarded and the sediment was inoculated onto Nutrient agar for isolation of E. coli. The isolates were characterized using conventional microbiological methods. The bacteria isolates were subjected to antibiotic susceptibility testing using the agar diffusion method. The Prevalence of E. coli in the urine sample of UTI patients showed 44 out of 50 samples were positive for E. coli which accounted for $88 \%$. Higher incidence of E. coli was found among subjects of age between $41-70$ years. The result showed high sensitivity of isolates to gentamicin (82\%), ciprofloxacin (75\%), streptomycin (70\%) and chloramphenicol (65\%). On the other hand, high degree of resistivity rates to ampicillin (85\%), amoxicillin (85\%), septrin (90\%), erythromycin (75\%) and tetracycline $(75 \%)$ were detected. Escherichia coli are one of the leading causes of urinary tract infections in humans.
\end{abstract}

Keywords: Antibiotics, Escherichia coli, prevalence, resistance, susceptibility

\section{INTRODUCTION}

Many human diseases are as result of infections caused by pathogenic bacteria, either internal or external of the human host. One of such bacterial infection is urinary tract infection (UTI), involving the presence of bacteria in the urinary tract (UT) which is naturally sterile [1]. Urinary tract infection (UTI) describes microbial colonization or inflammation of the bladder (cystitis), urethra (urethritis), or renal pelvis and kidneys (pyelonephritis). It is caused by the presence and growth of microorganisms in the urinary tract, which are the single commonest bacterial infections of all age groups [2].

Bacteria are the primary organisms that cause UTI. The urinary tract infection is commonly caused by gram negative bacilli bacteria in the family Enterobacteriaceae and usually belongs to genera Escherichia, Proteus, Klebsiella, Enterobacter and Pseudomonas [3]. Urinary tract infection is mainly caused by gramnegative organisms that include E. coli $60-70 \%$, Klebsiella 10\%, Proteus 5-10\%, and Pseudomonas 2-5\% and gram-positive bacteria, group B Streptococcus and Staphylococcus species [4]. According to Ronaldo [5], the common etiologic agents of UTI include Escherichia coli, Klebsiella spp, Staphylococcus aureus, Pseudomonas spp and Streptococcus. Bacteria colonization of the urinary tract is predominantly caused by Gram-negative species, such as Escherichia coli, Klebsiella, Proteus and Pseudomonas and rarely, by Grampositive organisms such as haemolytic Streptococci and Staphylococcus saprophyticus. Gram positive bacteria cause $15-20 \%$ while negative bacteria cause $80-85 \%$ [6]. Among gram negative Escherichia coli is the most frequent pathogen [7] but in complicated UTI the prevalence of other antibiotic resistance organisms increases such as Klebsiella, Proteus, Seratia, Enterobacter and Pseudomonas. 
Among gram positives $S$. saprophyticus, $E$. faecalis, $S$. pyrogenes, and $S$. aureus are usually prevalent and are resistant to variety of antibiotics [8].

Distribution of urinary pathogens and their susceptibility to antibiotics varies regionally so it becomes necessary to have knowledge of distribution of these pathogens and their susceptibility to antibiotics in a particular setting [9]. Most commonly isolated organisms although a variety of culture can cause UTIs, most are due to E. coli, bacteria that are common in the digestive tract and routinely found in stool other bacteria that may cause UTIs include species of Klebsiella, Enterococcus and Staphylococcus. Bacteria known as $E$. coli cause the majority of lower urinary tract infections. Escherichia coli are the most commonly encountered member of the family Enterobacteriaceae in the normal colonic flora and the most common cause of opportunistic infections [10]. Escherichia coli are gram-negative, non-sporing bacilli with most strains being motile and generally possessing both sex pili and adhesive fimbriae [11]. Because most strains rapidly ferment lactose, colonies grown on MacConkey media are smooth, glossy, and translucent and are rosepink in colour. Some Strains grown on Blood agar, result in colonies being surrounded by zones of haemolysi s. Colonies are smooth, circular, $1-1.5 \mathrm{~mm}$ in diameter and yellow opaque if lactose fermenting (blue, if nonlactose fermenting) when grown on Cystinelactose-electrolyte deficient (CLED) medium [12]. This microorganism is usually susceptible to a variety of antibiotics, such as Trimethoprim, Sulphamethozole, ciprofloxacin and Nitrofurantoin. The study was aimed to determine the prevalence and antibiotic susceptibility pattern of Escherichia coli isolated from urinary tract infection patients in Kano, Nigeria.

\section{Material And Methods}

\subsection{Study Area}

The study was conducted at Urology clinic of Aminu Kano Teaching Hospital Kano (AKTH). Kano state is located in the North-west Nigeria with coordinates $11^{0} 30 \mathrm{~N} 8^{0} 30 \mathrm{E}$. It shares borders with Kaduna state to the south- west, Bauchi state to the South-East, Jigawa state to the East, Katsina state to the West and Niger republic to the North. It has a total area of $20,131 \mathrm{~km}^{2} \quad(7,777 \mathrm{sqm})$ and population of $11,058,300$ [13].

\subsection{Ethical Clearance}

An approval for the study was obtained from Research and Ethic committee of Aminu Kano Teaching Hospital Kano. The aim of the study was explained clearly to the clients and informed consent obtained before proceeding to the study.

\subsection{Study Population}

A total of 50 (21 males and 29 females) urine samples were collected from UTI patients attending urology clinic of Aminu Kano Teaching Hospital Kano for period of 6 month from December 2016 to May, 2017.

\subsection{Samples Collection}

Early morning mid-stream urine samples of about ten (10) $\mathrm{ml}$ were collected using clean and sterilized plastic bottles with air-tight screw cap tops. Each urine sample bottle was labeled with a reference code, age, sex, and time of collection. The samples were placed in a cold box for transportation to the laboratory, where it was stored until analyses were carried out. Ten (10) $\mathrm{ml}$ of each urine sample was centrifuged at 2000 revolution per minute (rpm) for 5 minutes, the supernatant was discarded and the sediment was used for microbial culture.

\subsection{Isolation of Escherichia coli}

Isolation of $E$. coli was conducted according to the method describe by Prescott et al. [14]. During the process, a sterile wire loop was deep into the sediments of urine sample of the patients and streaked onto the surface of Nutrient agar (Life save Biotech, USA). The procedure was repeated for all the sample and the plates were incubated $37^{\circ} \mathrm{C}$ for 24 hours. The presumptive colony of $E$. coli from each plate was further sub-cultured to obtained pure culture. The pure isolates of E. coli were preserved in peptone water for further use.

\subsection{Identification of Escherichia coli}

The preserved isolates were confirmed as E. coli using conventional microbiological methods which include Gram staining, lactose fermentation, cystine-lactose-electrolyte deficient (CLED) medium growth and motility test as well as biochemical (Indole, methyl orange, voges proskauer, nitrate reduction and citrate utilization) tests according to the methods described by Holt et al. [15].

\subsection{Gram Staining}

Gram staining was done according to method described by Cheesbrough [6]. A thin smear was made by emulsifying an overnight culture of the 
isolate in normal saline on a well labeled clean glass slide. The smear was air dried and fixed by heat. This is followed by flooding the slide with crystal violet as primary stain for 30 seconds and then rinsed the slide with distilled water. The smear was flooded with Lugol's iodine as a mordant to fix the primary stain and then rinsed with distilled water after 60 seconds. The slide was decolorized using acetone and rinsed immediately. Counter stain with safranin followed and left for 30 before being rinsed off. The stain smear was air dried and observed under microscope.

\subsection{Biochemical test}

\subsubsection{Indole Test}

The tested organism was inoculated into peptone water and incubated at $37^{\circ} \mathrm{C}$ for overnight, the kovacis reagent was added. If there is pink ring the result was indicated as positive. If there is no pink ring in the surface the result was indicated as negative.

\subsubsection{Citrate Utilization Test}

In this test organism has ability to use citrate as only source of carbon. By straight loop apart of tested colonies was emulsified in kosser's citrate media and incubated at $37^{\circ} \mathrm{c}$ for 24 hours. A blue color with growth indicated as positive, no change in color indicated the negative result.

\subsubsection{Methyl Red and Voges Proskauer Test}

A pure culture of the test organism was inoculated in the MR/VP broth and incubated at $35^{\circ} \mathrm{C}$ for 24 hours. Five Drops of MR reagent was added to the broth. A pure culture of the test organism was inoculated into MR/VP broth and incubated for 24 hours at $37^{\circ} \mathrm{C}$. An aliquot of 1 $\mathrm{ml}$ of the broth was added into a sterile test tube and add $0.6 \mathrm{ml}$ of VP reagent was added and shaken gently, then allowed it to expose into the atmosphere for 15 minutes.

\subsubsection{Nitrate Reduction Test}

Nitrate broth was inoculated with an isolate of the test organism using sterile inoculating loop and incubated at $37^{\circ} \mathrm{C}$ for 24 hours. A dropper full of sulfanilic acid and that of $\alpha$ naphthalamine were added to the broth.

\subsubsection{Motility Test}

The isolate was inoculated into motility medium by a fine stab with a sterile needle to a depth of $2 \mathrm{~cm}$ length of the bottom of the tube. It was then incubated at $37^{0} \mathrm{C}$ for 24 hours. Line of inoculation was defined and the medium was cleared for non motile organism while the line of inoculation was not defined for motile organism and the rest of the medium was somewhat cloudy for the motile organisms [6].

\subsubsection{Antibiotic Susceptibility Testing}

The bacteria isolates were subjected to antibiotic susceptibility testing using the agar diffusion method as described by Bauer et al. [16]. Mueller Hinton agar (MHA) plates were inoculated with overnight culture of each isolate by streak plating. The standard antibiotic sensitivity discs were then aseptically placed at equidistance on the plates and allowed to stand for 1 hour. The plates were then incubated at $37^{\circ} \mathrm{C}$ for 24 hours. Sensitivity pattern of the isolates to Ampicillin (30 $\mu \mathrm{g})$, Streptomycin (30 $\mu \mathrm{g})$, Augmentin $(10 \mu \mathrm{g})$, Erythromycin $(30 \mu \mathrm{g})$, Amoxacillin $(30 \mu \mathrm{g})$, Chloramphenicol $(30 \mu \mathrm{g})$, Gentamicin $(10 \mu \mathrm{g})$, Tetracycline $(30 \mu \mathrm{g})$, Ciprofloxacin $(10 \mu \mathrm{g})$ and Septrin $(30 \mu \mathrm{g})$ produced by Abtek pharmaceutical limited, were determined. Isolates were divided into three groups based on the zone of inhibition produced by the antibiotic disc; susceptible, intermediate susceptible and resistant according to the European committee on antimicrobial susceptibility testing (EUCAST) breakpoint for interpretation of MICs and zone diameters [17].

\section{RESULTS}

\subsection{Demographic Distribution of the Subjects}

Table1. Demographic Distribution of the Subjects with Percentage Prevalence

\begin{tabular}{|c|c|c|}
\hline Parameters & Number & Prevalence (\%) \\
\hline Age (years) & & \\
\hline Less than 18 & 01 & 2 \\
\hline $18-40$ & 16 & 32 \\
\hline $41-70$ & 28 & 56 \\
\hline $71-$ above & 05 & 10 \\
\hline Sex & & \\
\hline Male & 21 & 42 \\
\hline Female & 29 & 58 \\
\hline Marital status & & \\
\hline Single & 08 & 16 \\
\hline Married & 42 & 84 \\
\hline Types of resident & & \\
\hline Urban & 19 & 38 \\
\hline Rural & 31 & 62 \\
\hline
\end{tabular}

The Demographic distribution of the subjects is presented in Table 1. A total of 50 subjects (21 males and 29 females) participated in the study, all of which are patients diagnosed with urinary tract infection. The age category, sex, marital status and type of resident were considered for demographic distribution of the subjects.

\subsection{Identification of Escherichia coli}

The result for identification of $E$. coli is presented in Table 2 below. The isolate was 
identified based on Gram staining, cultural characteristics and biochemical test. The result showed that the isolate is Gram negative bacteria, positive for MR and motility test but negative for indole, VP and citrate utilization test. The isolate cannot ferment lactose and produce transparent colourless colony in both MacConkey and CLED agar

Table2. Morphological and Biochemical Characterization of E. coli

\begin{tabular}{|l|c|c|}
\hline S/N & Test & Inference \\
\hline 1 & Gram staining & - \\
\hline 2 & Indole & + \\
\hline 3 & Methyl-red & + \\
\hline 4 & Voges Proskauer & - \\
\hline 5 & Citrate utilization & - \\
\hline 6 & Nitrate reduction & + \\
\hline 7 & Motility & + \\
\hline 8 & Lactose fermentation & + \\
\hline 9 & CLED medium growth & $\begin{array}{c}\text { Opaque yellow } \\
\text { colony }\end{array}$ \\
\hline
\end{tabular}

\subsection{Prevalence of Escherichia coli}

The Prevalence of E. coli in the urine sample of UTI patients is presented in Table 2. The result showed 44 out of 50 samples were positive for

Table4. Antibiotic Sensitivity testing of the E. coli against some antibiotics

\begin{tabular}{|l|l|l|l|l|}
\hline \multicolumn{1}{|c|}{ Antibiotics } & Conc. $(\boldsymbol{\mu g})$ & Sensitive n (\%) & \multicolumn{1}{|c|}{ Intermediate n (\%) } & \multicolumn{1}{|c|}{ Resistance n (\%) } \\
\hline Ampicillin & $30 \mu \mathrm{g}$ & $0(0)$ & $7(15)$ & $37(85)$ \\
\hline Streptomycin & $30 \mu \mathrm{g}$ & $31(70)$ & $4(10)$ & $9(20)$ \\
\hline Augmentin & $10 \mu \mathrm{g}$ & $12(27)$ & $10(23)$ & $22(50)$ \\
\hline Erythromycin & $30 \mu \mathrm{g}$ & $7(15)$ & $4(10)$ & $33(75)$ \\
\hline Amoxicillin & $30 \mu \mathrm{g}$ & $0(0)$ & $7(15)$ & $37(85)$ \\
\hline Chloramphenicol & $30 \mu \mathrm{g}$ & $29(65)$ & $2(5)$ & $13(30)$ \\
\hline Gentamicin & $10 \mu \mathrm{g}$ & $36(82)$ & $6(13)$ & $2(5)$ \\
\hline Tetracycline & $30 \mu \mathrm{g}$ & $4(10)$ & $7(15)$ & $33(75)$ \\
\hline Ciprofloxacin & $10 \mu \mathrm{g}$ & $33(75)$ & $4(9)$ & $7(16)$ \\
\hline Septrin & $30 \mu \mathrm{g}$ & $0(0)$ & $4(10)$ & $40(90)$ \\
\hline
\end{tabular}

Key: $n=$ frequency, $\%$ = percentage

\section{DISCUSSION}

Urinary Tract Infections are caused by microbial invasion and subsequent multiplication in urinary tract. The results of this study on prevalence of urinary tract infection among the subjects showed that prevalence was high in individuals between the ages of $41-70$ years with about $56 \%$ prevalence consisting of 28 out of 50 subjects. This difference in prevalence could be based on differences in sanitary conditions and observed personal hygiene. More female were recorded in the study than male. This is in accordance with previous study conducted by Shah et al. [18]. Higher female patient is associated with combination of urinary and genital system as well as other factors such as pregnancy. The finding of the presence study
E. coli which accounted for 88\%. Higher incidence of $E$. coli was found among subjects of age between 41-70 years.

Table3. Prevalence of E. coli in the urine sample of UTI patients

\begin{tabular}{|c|c|c|c|}
\hline Age (year) & $\begin{array}{c}\text { Frequency } \\
(\mathbf{n})\end{array}$ & $\begin{array}{c}\boldsymbol{E} . \text { coli } \\
+(\mathbf{n})\end{array}$ & $\begin{array}{c}\text { Prevalenc } \\
\text { e }(\boldsymbol{\%})\end{array}$ \\
\hline Less than 18 & 01 & 01 & 02 \\
\hline $18-40$ & 16 & 15 & 30 \\
\hline $41-70$ & 28 & 23 & 46 \\
\hline $70-$ above & 05 & 05 & 10 \\
\hline Total & 50 & 44 & 88 \\
\hline
\end{tabular}

\subsection{Antibiotic Sensitivity Testing}

The sensitivity and resistivity of E. coli against the antibiotics used is presented below (Table 4). Some of the antibiotics were active against the isolates while resistance to others. The result showed high sensitivity of isolates to gentamicin (82\%), ciprofloxacin (75\%), streptomycin (70\%) and chloramphenicol (65\%). On the other hand, high degree of resistivity rates to ampicillin (85\%), amoxicillin (85\%), septrin $(90 \%)$, erythromycin $(75 \%)$ and tetracycline (75\%) were detected. revealed higher prevalence $(88 \%)$ of $E$. coli in the urine samples of UTI patients. E. coli was observed as the most common etiologic agent of UTI, which is also in accordance with previous studies [19,20]. Rate of E. coli isolation was highest in elderly patients $(41-70$ years $)$. This finding was in conformity with that of Iqbal [21]. The pathogenic ability of E. coli is largely affordable by the flexible gene pool through the gain and loss of materials [22, 23]. Antibiotic resistant isolates of $E$. coli, especially those that are floroquinolones resistant and those producing extended spectrum B-lactamases have increased significantly during the 2000's and in certain areas while many nosocomial and community-acquired $E$. coli are now resistant to several important antimicrobials [24]. 
In this study, the overall resistance of E. coli to antimicrobials was high. The result showed high sensitivity of isolates to gentamicin (82\%), ciprofloxacin $(75 \%)$, streptomycin $(70 \%)$ and chloramphenicol $(65 \%)$. On the other hand, high degree of resistivity rates to ampicillin (85\%), amoxicillin (85\%), septrin (90\%), erythromycin $(75 \%)$ and tetracycline $(75 \%)$ were detected. The result is consistent with the findings of previous studies. The resistance rate in this study was in conformity with that of Khan et al. [25]. High resistance rate of $E$. coli to ampicillin and amoxicillin in this study justify the study conducted by Sabir et al. [26] who reported $100 \%$ resistant of E. coli to beta lactam drugs. Resistance to tetracycline and erythromycin in this study was in line with the study conducted by Andargachew et al. [27] and Petkovsjek et al. [28] in Sudan and Slovenia respectively. One of the major reasons for this high resistance can be co-expressed resistance mechanisms in the species. Increasing rates of antimicrobial resistance among $E$. coli is a growing concern worldwide. Antimicrobial resistance in E. coli has been reported worldwide and increasing rates of resistance among $E$. coli is a growing concern in both developed and developing countries. The higher resistance against the above antimicrobials could be as a result of repeated or prolonged use or exposure of uropathogens to antibiotics repeated use of antibiotics can damage urethral flora, allowing uropathogens to colonize and subsequently to infect the urinary tract, leaving clinicians with very few choices of drugs for the treatment of UTI $[28,29]$. Moreover, this condition enables bacteria to exchange their genetic material through horizontal gene transfer resulting in resistant gene that confer resistance to particular antibiotics [30]. In this study, E. coli isolates were sensitive to gentamicin, ciprofloxacin, streptomycin and chloramphenicol. Similar studies conducted by Okonko et al. [31] in Nigeria have reported comparable susceptibility rates. High sensitivity to ciprofloxacin and gentamicin was also recorded from previous studies conducted in India [32].

\section{CONCLUSION}

Escherichia coli are one of the leading causes of urinary tract infections in humans. The finding of this study revealed that $E$. coli was observed as the most common etiologic agent of UTI. Its prevalence accounted for $88 \%$ of the urine samples examined. The result showed high sensitivity of the isolates to gentamicin (82\%), ciprofloxacin (75\%), streptomycin (70\%) and chloramphenicol (65\%). On the other hand, high degree of resistivity rates to ampicillin (85\%), amoxicillin (85\%), septrin (90\%), erythromycin $(75 \%)$ and tetracycline $(75 \%)$ were detected. The judicious use of antibiotic is recommended which will help to limit the increasing rate of drug resistance in the pathogens.

\section{ACKNOWLEDGEMENT}

The authors wish to acknowledge the staff of urology clinic of Aminu Kano Teaching Hospital Kano for samples provision. Thanks to Microbiology Department, Kano University of Science and Technology Wudil, Kano for use of Laboratory facilities.

\section{REFERENCES}

[1] Zorc JJ, Kiddoo DA and Shaw KN. Diagnosis and Management of Pediatric Urinary Tract Infections. Clinical Microbiology Reviews.2005; 18, 417-422.

[2] Muhammad Ali, Kabiru AG and Muhammad SA. Antibiotic susceptibility profile of bacteria responsible for urinary tract infection (UTI), South Asian Journal of Biological Research, 2018; 1(1): 12-27

[3] Wammanda RD, Aihionbare HA and Ogala WN. Use of nitrite dipstick test in the screening of urinary tract infection in children. West African Journal of Medicine. 2000; 19:31 -33.

[4] Alemu A, Moges F, Shiferaw Y, Tafess K, Kassu A and Anagaw B. Bacterial Profile and drug susceptibility pattern of urinary tract infection in pregnant women at University of Gondar Teaching Hospital, Northwest Ethiopia, BMC Research 2012; 5(197).

[5] Ronaldo A. The etiology of urinary tract infections: traditional and emerging pathogens. Dis Mon. 2003; 49(2):71-82.

[6] Cheesbrough M. District laboratory practice in tropical countries, second edition in New York in USA, chapter 7, 2009; pp (132-304).

[7] Gales AC, Sader HS and Jones RN. Urinary tract infection trends in Latin American Hospitals. Diagn. Microbiol. Infect. Dis., 2002; 44: 289-299.

[8] Thomas JG. Urinary Tract Infections. In: Diagnostic Microbiology. (Eds Mahon, C.R.and G. Manuselis).1995; Pp: 950-969

[9] Baron S. Medical Microbiology, 4th edition. The University of Texas Medical Branch at Galveston, Texas USA 1996.

[10] Sherris J. Medical Microbiology. Edition 4th. The McGraw-Hill Companies, Inc.USA. 1984.

[11] Forbes BA, Sahm DF and Weissfeld AS. Diagnostic microbiology, Elsevier book AID.2007 
[12] Foxman B. (2002). Epidemiology of urinary tract infections; incidence, morbidity, and economics cost. Am J med, 2002; 113 suppl 1A:5-13.

[13] National Population Commission (NPC). National population census result, 2006 Abuja Nigeria

[14] Presscot LM, Harley JP and Klein DA. Microbiology Sixth edition. McGraw Hill International edition New York 2005.

[15] Holt, J.G, Krieg, N.R, Sneath, P.A, Stanley, JT and Williams ST. Bergey's manual of systematic bacteriology, 9th edition. Williams \& Wilkins Co. Baltimore, Maryland, 1994; p786.

[16] Bauer AW, Kirby WM, Sherris JC and Turck M. Antibiotic susceptibility testing by a standardized single disk method. Am J Clin Pathol. 1996; 45: 493-496.

[17] EUCAST, European committee on antimicrobial susceptibility testing (2015) breakpoint for interpretation of MICs and zone diameters (2015).

[18] Shah PS, Cannon JP, Sullivan CL, Nemchausky B, Pachucki CT. Controlling antimicrobial use and decreasing microbiological laboratory tests for urinary tract infections in spinal-cord-injury patients with chronic indwelling catheters. Am J Health Syst Pharm. 2005;62(1):74-77.

[19] Singh V, Jaryal M, Gupta J, Kumar P. Antibacterial Activity Of Medicinal Plants Against Extended Spectrum Beta Lactamase Producing Bacteria Causing Urinary Tract Infection. Int J Drug Res Tech. 2012;2:263267.

[20] Dimitrov TS, Udo EE, Emara M, Awni F, Passadilla R. Etiology and antibiotic susceptibility patterns of community-acquired urinary tract infections in a Kuwait hospital. Med Princ Pract. 2004;13 (6):334-339.

[21] Iqbal MK, Patel IK. Susceptibility patterns of Escherichia coli: Prevalence of multidrugresistant isolates and extended spectrum betaLactamase phenotype. J Pak Med Asso. 2002; 52: 407-417.

[22] Wiles TJ, Kulesus RR, Mulvey MA. Origins and Virulence mechanisms of Uropathogenic Escherichia coli. Experimental and Molecular Pathology 2008; 85: 11-19.

[23] Ulett GC, Totsika M, Schaale K, Carey AJ, Sweet MJ, et al. Uropathogenic Eschericha coli virulence and innate immune responses during urinary tract infection. Current Opinion in Microbiology 2013; 16: 100-107.

[24] Pitout JD (2012) Extraintestinal pathogenic Escherichia coli: an update on antimicrobial resistance, Laboratory diagnosis and treatment. Expert Review on Anti Infective Therapy 2012; 10: 919-928.

[25] Khan NA, Saba N, Abdus S, Ali AQ. Incidence and antibiogram patterns of $E$. coli isolates from various clinical samples from patients at NIH Islamabad. Pak J Biol Sci. 2002; (1):111113.

[26] Sabir S, Anjum AA, Ijaz T, Ali MA, Khan MR, Nawaz M. Isolation and antibiotic susceptibility of E. coli from urinary tract infections in a tertiary care hospital. Pak J Med Sci 2014;30(2):389-392. doi: http://dx.doi.org/10. 12669/pjms.302.4289

[27] Andargachew M, Feleke M, Tesesma B, Afewerk K. Pattern and multiple drug resistance of bacterial pathogens isolated from wound infection at University of Gondar Teaching Hospital, Northwest Ethiopia. Ethiop Med J. 2006; 44(2): 125-31.

[28] Petkovsjek Z, Elersjic; K, Gubina M, $Z_{i}$ gurBertok D, Erjavec S. Virulence potential of Escherichia coli isolates from skin and soft tissue infections. J Clin Microbiol. 2009; 47(6): 1811-1817.

[29] Hiller S., Roberts, Z., dunstan F. butler C., howard A., palmer. S., (2007). Prior antibiotics and risk of antibiotic resistant community acquired urinary tract chemotheraphy. 2007; 60(1): 92-9.

[30] Tessema B. and Tanagho, E.A. Predominant isolates of urinary tract pathrogens and their antimicrobial susceptibility patterns in gondar university teaching hospital, northwest Ethiopia.2007.

[31] Akonko IO. Soleye FA, Amusan TA, Ogun AA, Ogunnusi TA Ejembi J. Incidence of multi-drug $r$ esistance (MDR) organisms in Abeokuta, Southwestern Nigeria. Global J Pharm. 2009; 3(2): 69-80.

[32] Bharathi MJ, Ramakrishnan R, Meenakshi R, Palaniappan R. In-Vitro efficacy of antibacterials against bacterial isolates from corneal ulcers. Indian J Ophthalmol. 2002; 50: 109-114.

Citation: Farouk S. Nas, Muhammad Ali, Muhammad S. Abdallah, Abubakar U. Zage. Prevalence and Antibiotic Susceptibility Pattern of Escherichia Coli Isolated from Urine Samples of Urinary Tract Infection Patients. ARC Journal of Urology.2019; 4(1): 14-19. doi:dx.doi.org/10.20431/2456-060X.0401004.

Copyright: (C) 2019 Authors. This is an open-access article distributed under the terms of the Creative Commons Attribution License, which permits unrestricted use, distribution, and reproduction in any medium, provided the original author and source are credited. 